\title{
Response: to Letter regarding "Super-selective balloon test occlusion with electrophysiological monitoring to occlude angiographically invisible posterior communicating artery perforators with unruptured aneurysm"
}

\author{
Daisuke Maruyama $^{1}\left[\right.$ [ Masataka Nanto ${ }^{1} \cdot$ Naoya Hashimoto $^{1}$
}

Received: 28 January 2022 / Accepted: 30 January 2022 / Published online: 5 February 2022

(c) The Author(s), under exclusive licence to Springer-Verlag GmbH Austria, part of Springer Nature 2022

\section{Dear Editor:}

We would like to thank Mugikura et al. for their compliments regarding our article entitled "Super-selective balloon test occlusion with electrophysiological monitoring to occlude angiographically invisible posterior communicating artery perforators with unruptured aneurysm" [2]. We are glad to be given the opportunity to clarify certain microanatomical considerations.

The perforators arising from the rostral part of the posterior communicating artery (PcomA), called the hypothalamic or tuberoinfundibular branches, help maintain blood supply in the hypothalammopituitary region [1]. We agree with Mugikura et al. that the occlusion of these perforators may lead to an infarction in the pars tecta of the column of the fornix or mammillary body. Since this belongs to the Papez memory circuit [3], an infarction in this area could cause memory disturbance. In our report, though an infarction in the ipsilateral anterior thalamus was noted after coil embolization of the PcomA aneurysm and proximal portion of the PcomA, the patient showed no neurological deficits. However, formal neuropsychological examinations on memory were not conducted. Further studies on a large number of patients treated surgically or interventionally for PcomA aneurysms, using both diffusion-weighted images and formal neuropsychological examinations, are necessary.

This article is part of the Topical Collection on Vascular Neurosurgery - Aneurysm

Daisuke Maruyama d.maru1214@gmail.com

1 Department of Neurosurgery, Kyoto Prefectural University of Medicine Graduate School of Medical Science, 465 Kajii-cho, Kawaramachi Hirokoji, Kamigyo-ku, Kyoto 602-8566, Japan
The perforators supplying the hypothalammopituitary region are reported to have possible anastomoses in the optic or tuberoinfundibular branches of the internal carotid artery, superior hypophyseal artery, and mamillary and tuberoinfundibular branches of the PcomA [1]. This shows that extent of such anastomoses may be associated with the presence and severity of ischemic symptoms after interventions for PcomA lesions. In the future, we wish to establish preoperative imaging findings that would aid in evaluating microanatomical collaterals and precise intraoperative monitoring methods to monitor symptoms of memory disturbance.

\section{Declarations}

Competing interests The authors declare no competing interests.

\section{References}

1. Marinković SV, Milisavljević MM, Marinković ZD (1989) Microanatomy and possible clinical significance of anastomoses among hypothalamic arteries. Stroke 20:1341-1352

2. Maruyama D, Nanto M, Ogita S, Kishida K, Fujiwara G, Murakami M, Murakami N, Hashimoto N (2022) Super-selective balloon test occlusion with electrophysiological monitoring to occlude angiographically invisible posterior communicating artery perforators with unruptured aneurysm. Acta Neurochir (Wien) 164:169-172

3. Mugikura S, Kikuchi H, Fujii T, Murata T, Takase K, Mori E, Marinković S, Takahashi S (2014) MR imaging of subcallosal artery infarct causing amnesia after surgery for anterior communicating artery aneurysm. AJNR Am J Neuroradiol 35:2293-2301

Publisher's note Springer Nature remains neutral with regard to jurisdictional claims in published maps and institutional affiliations. 